\title{
Erratum to: Coping with chaos: unpredictable food supplies intensify torpor use in an arid-zone marsupial, the fat-tailed dunnart (Sminthopsis crassicaudata)
}

\author{
Adam J. Munn • Pippa Kern • Bronwyn M. McAllan
}

Published online: 5 October 2010

(C) Springer-Verlag 2010

\section{Erratum to: Naturwissenschaften}

\section{DOI 10.1007/s00114-010-0670-2}

Unfortunately, there are two errors in the original manuscript which require correction to ensure repeatability of our methods;

(1) The amount of food offered to the animals in the Restricted Diet treatment should have been reported as $75 \%$, and not $70 \%$, of ad libitum intakes (see Abstract, line 18, and Methods, paragraph 1, line 20).

(2) The amounts of food offered to animals in the Unpredictable Diet treatment were reported incorrectly. The Unpredictable Diet treatment actually consisted of five possible and randomly allocated feeding levels of $0 \%, 30 \%, 70 \%, 100 \%$ and $120 \%$ of ad libitum intakes (see Methods, paragraph 1, line 21).

These corrections do not impact the outcomes or the biological or statistical significance of the results.

The online version of the original article can be found at http://dx.doi. org/10.1007/s00114-010-0670-2.

\footnotetext{
A. J. Munn · P. Kern

Faculty of Veterinary Science, The University of Sydney,

Sydney, NSW 2006, Australia

B. M. McAllan

Discipline of Physiology School of Medical Sciences, and Bosch Institute, The University of Sydney,

Sydney, NSW 2006, Australia

Present Address:

A. J. Munn $(\square)$

School of Biological Sciences, The University of Wollongong,

Wollongong, NSW 2522, Australia

e-mail: amunn@uow.edu.au
} 